\title{
Self-persuasion as marketing technique: the role of consumers' involvement
}

\author{
Stefan F. Bernitter \\ Amsterdam School of Communication Research, University of Amsterdam, \\ Amsterdam, The Netherlands \\ Iris van Ooijen \\ Leiden University, Leiden, The Netherlands, and \\ Barbara C.N. Müller \\ Behavioural Science Institute, Radboud University, Nijmegen, \\ The Netherlands
}

\begin{abstract}
Purpose - This paper aims to demonstrate that self-persuasion can be used as a marketing technique to increase consumers' generosity and that the efficacy of this approach is dependent on consumers' involvement with target behavior.

Design/methodology/approach - An experimental field-study was conducted to investigate the effects of self-persuasion versus direct persuasion attempts versus no persuasion attempts on consumers' tipping behavior in a lunchroom. Additionally, in a lab experiment, the moderating role of involvement on self-persuasion versus direct persuasion was tested.

Findings - The results reveal that self-persuasion is more effective than direct persuasion attempts or no persuasive messages in increasing consumers' generosity. This is moderated by consumers' involvement with the target behavior. For consumers with high involvement, self-persuasion is more effective than direct persuasion, while no differences were found for consumers with moderate or low involvement.

Practical implications - The scope of self-persuasion is not limited to the inhibition of undesired behavior, but it also extends to the facilitation of desired behavior, which considerably broadens the scope of this technique. Self-persuasion might be used as a marketing technique to influence consumers' purchase behavior. This might be particularly viable in situations in which consumers feel high involvement with products or behavior.
\end{abstract}

Originality/value - Recently, research in health psychology demonstrated that self-persuasion is a very effective way of inhibiting undesired, addictive behavior and being more successful than direct persuasion. Yet, insufficient knowledge is available about the efficacy of self-persuasion with regard to promoting other

C Stefan F. Bernritter, Barbara C.N. Müller and Iris van Ooijen. Published by Emerald Publishing Limited. This article is published under the Creative Commons Attribution (CC BY 3.0) licence. Anyone may reproduce, distribute, translate and create derivative works of this article (for both commercial and non-commercial purposes), subject to full attribution to the original 43 publication and authors. The full terms of this licence may be seen at http://creativecommons.org/ licences/by/3.0/legalcode

The authors would like to thank Rick van Baaren, Renske van Bronswijk, Matthijs van Leeuwen and Peeter Verlegh for comments on earlier versions of this paper. The authors also want to thank the two anonymous reviewers and the $\mathrm{AE}$ for their very valuable comments and guidance during the review process. Moreover, many thanks to the team of "Café de Blonde Pater" in Nijmegen, The Netherlands, for their help with the data collection of Study 1.

Self-persuasion

as marketing technique

1075

Received 19 April 2015

Revised 27 January 2016

15 August 2016

1 November 2016

Accepted 12 December 2016

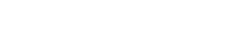

(n) 
EJM

$51,5 / 6$

target behaviors. In particular, its potential as a marketing technique to influence consumers' behavior and its boundary conditions are still understudied.

Keywords Consumer behaviour, Involvement, Generosity, Tipping, Indirect persuasion, Self-persuasion

Paper type Research paper

\section{6}

What makes people buy products, pay higher prices, volunteer for a good cause or increase their tip in a restaurant? Researchers and practitioners are eager to discover when and how persuasion is effective in influencing consumers. More specifically, a substantial body of research in marketing and related fields is dedicated to indirect techniques of persuasion. Rather than directly providing consumers with arguments or simply requesting them to change their behavior, indirect techniques are more subtle and unconscious. Examples are framing techniques (Gamliel and Herstein, 2012; Krishen et al., 2014; McKechnie et al., 2012), the foot-in-the-door technique (Fennis et al., 2009; Freedman and Fraser, 1966; Pascual et al., 2013), low-balling (Burger et al., 1981; Cialdini et al., 1978), door-in the-face technique (Burger, 1999; Cialdini et al., 1975) and disrupt-then-reframe technique (Davis and Knowles, 1999; Fennis et al., 2004). Approaching consumers in an indirect manner reduces the possibility that consumers show reactance to persuasion (Fransen et al., 2015), which is one of the major disadvantages of direct persuasion techniques (Aronson, 2007). Indirect persuasion enhances the likelihood that a persuasion attempt will succeed (Brehm, 1966; Lunardo and Roux, 2015).

Recently, another indirect persuasion technique has shown promising results in the domain of health psychology and addictive behaviors: self-persuasion. This involves encouraging consumers to generate arguments about a certain concept or behavior themselves, instead of providing them with arguments to persuade them (Kardes et al., 2001; Müller et al., 2016). Currently, the application of this technique is mostly limited to the health domain, where traditionally a clear injunctive norm about the target behavior is communicated by governments and other institutions (e.g. warning labels on cigarette boxes; Hamilton et al., 2008). As demonstrated by Müller et al. (2009), communicating an injunctive norm via direct persuasion is an inferior technique compared to using self-persuasion in relation to changing smoking behavior. Although the self-persuasion technique seems promising in changing behavior, the context in which self-persuasion has been studied is of limited relevance to marketers. In addition, effects of self-persuasion have primarily been shown in controlled lab environments, and our knowledge about boundary conditions of this technique is scarce (for the few exceptions to this, see, for instance, Damen et al., 2015; Kardes et al., 2001; Müller et al., 2017).

In sum, the aims of the present paper are threefold:

(1) First, it aims to replicate earlier findings about self-persuasion and explore whether this technique is also useful in increasing desirable consumer behavior for which no clear injunctive norms are present (i.e. tipping; Studies 1 and 2).

(2) The second aim is to put effects of self-persuasion to the test in a real-life setting outside the lab with a non-student sample (Study 1).

(3) Third, this paper aims to demonstrate that self-persuasion is not always superior to more direct marketing strategies by showing that the effects of 
self-persuasion are conditional and depend on consumers' involvement with the target behavior (Study 2).

In doing so, we first explore the efficacy of self-persuasion as a marketing technique in technique a field setting on behavior for which there is no clear injunctive norm (i.e. tipping).

\section{Theoretical background}

Research has shown that information that is generated by oneself is perceived as more accurate and trustworthy and therefore more persuasive than information generated by an external source (Hoch and Deighton, 1989; Levin et al., 1988). According to Mussweiler and Neumann (2000), people have the tendency to correct for information that is provided by an external source, whereas they fail to correct for the influence of self-generated information. In other words, while people are able and likely to resist others' persuasion attempts (Knowles and Linn, 2004), they fail to resist attempts of persuading themselves. Moreover, individuals tend to come up with the most persuasive and compelling statements when they are asked to generate arguments (Greenwald and Albert, 1968; Slamecka and Graf, 1978). This suggests that it might be more effective to let people persuade themselves to affect consumer behavior.

The persuasion technique that makes use of this bias in favor of self-generated information is referred to as self-persuasion (Aronson, 2007). For example, Müller et al. (2009) demonstrated that self-persuasion is a more effective technique for inhibiting smoking behavior, compared to external persuasion attempts. Regular smokers, who were instructed to write down arguments against smoking, waited longer to light up a cigarette compared to smokers who read arguments against smoking provided by the experimenter. Recent research has since shown that it is not necessary to write down arguments to induce self-persuasion; an easily applicable method to induce self-persuasion is asking questions, which triggers people into coming up with arguments (Loman et al., 2015), a process which is assumed to be automatic (Fitzsimons and Williams, 2000). Several studies have demonstrated that merely presenting participants with questions (rather than statements) about why smoking is bad led to a higher smoking-related risk perception (Glock et al., 2013) and longer absence rates (Müller et al., 2016). In relation to other health-related behaviors, formulating questions instead of statements has been shown to lead to an increase in negative outcome expectancy perception (Krischler and Glock, 2015), lower alcohol consumption rates (Loman et al., 2015) and an increase in exercise behavior (Williams et al., 2006; for negative side-effects, however, see, Fitzsimons and Moore, 2008). Based on these findings, self-persuasion should be the first choice when trying to influence someone, irrespective of the behavior we try to change.

However, when it comes to smoking, drinking alcohol or exercise, most people are well-aware what they ought to be doing, often because of governmental campaigns that aim to promote a healthy lifestyle by communicating injunctive norms about health-related behavior. For example, since 2003, warning labels have been shown on cigarette packs, and alcohol commercials in The Netherlands are required to state that responsible alcohol consumption is advised. This distinction is important as, for instance, Glock and Kneer (2009) found that smokers, compared to non-smokers, were realistic about their higher chance of contracting a smoking-related illness (e.g. lung cancer). However, this awareness did not lead to higher relevance of the persuasive messages as might be assumed (Johnson and Eagly, 1989); rather, it seemed to result in some kind of immunization toward anti-smoking messages. In the same vein, most of the research that examined the influence of self-persuasion on behavior, mainly explored this by looking at addictive behaviors (Glock et al., 2013; Krischler and Glock, 2015; Müller et al., 2009, 2016), and it has been suggested that 
EJM

$51,5 / 6$

1078

the effectiveness of self-persuasion lies, among other things, in the fact that direct persuasion triggers defensive responses that help to justify the behavior (Liberman and Chaiken, 1992). In other words, people with addictive behaviors such as smoking in particular, may be immune to persuasion by direct arguments, because smokers may have developed defensive reactions as a response to repeated governmental campaigns that communicate injunctive norms. Thus, based on this research, it could be argued that for changing addictive behaviors, self-persuasion may be superior to communicating injunctive norms. It is unknown, however, whether this is also the case for behaviors that are less subject to injunctive norms (e.g. such as those advocated by governmental campaigns) and for which consumers are less likely to have developed strong defensive responses than is the case for addictive behaviors. In the present study, we put self-persuasion to the test with a type of consumer behavior for which no clear injunctive norm is communicated, leaving a tip in a lunchroom[1].

As a first step, the current study aims to demonstrate that self-persuasion is superior to direct persuasion attempts, also in cases in which injunctive norms are not officially communicated (e.g. by means of governmental campaigns). The literature discussed above suggests that consumers will comply more with a behavior after they formulate arguments themselves (i.e. self-persuasion), compared to a situation in which they read arguments that are provided by others (or a control condition).

H1. The use of self-persuasion is superior as a persuasion technique to the use of externally generated arguments in increasing desirable consumer behavior.

Yet, the question remains whether self-persuasion is always superior to providing consumers with externally generated arguments. For instance, it has been suggested that characteristics of the arguments (Kardes et al., 2001) and characteristics of the individual (Damen et al., 2015) can alter the effectiveness of self-persuasion. In the domain of addictive behavior, research has suggested that the effectiveness of self-persuasion relies on a high grade of self-involvement (Müller et al., 2009). Moreover, the domains in which effects of self-persuasion have been demonstrated (e.g. smoking, exercising and drinking) are all assumed to be highly self-involving types of behavior, as they are all related to people's health. Hence, it could be that the shown effects of self-persuasion are dependent on consumers' involvement with the target behavior, and self-persuasion might only be superior to direct forms of persuasion, when people are highly involved with the behavior that one desires to change.

This notion is in line with research that has shown that high involvement with an issue leads to more elaboration and deeper processing of messages (Petty et al., 1983). While, for direct persuasion, the positive effects of enhanced elaboration and deeper processing would be neutralized by an increase in resistance (Petty and Cacioppo, 1979), this would not be the case for self-persuasion, as consumers are not able to correct for the influence of self-generated information (Mussweiler and Neumann, 2000). By means of bypassing the threshold of consumers' resistance, an increase in elaboration and processing might positively affect the effectiveness of self-persuasive marketing messages. In low-involvement situations, however, this advantage of self-persuasion would not come into play, as consumers tend to make decisions based on rather peripheral cues in such cases and do not decide on the basis of argument strength or other centrally processed cues (Petty et al., 1981). Consequently, we hypothesize:

H2. If consumers feel highly involved with a target behavior, self-persuasion is more effective to increase this behavior in these consumers compared to providing them 
with pro-behavioral arguments. If consumers feel low or moderate involvement with the target behavior, there will be no difference between both the strategies.

In our studies, we focus on a particular type of involvement: enduring involvement, which is defined as "an individual difference variable representing the arousal potential of a product or activity that causes personal relevance" (Higie and Feick, 1989, p. 690). This type of involvement arises as a result of ongoing interest with behavior or products and its association with the consumer's self-concept, ego and values (Richins and Bloch, 1986). Enduring involvement is considered to be a stable trait (Richins et al., 1992) and is often contrasted with situational involvement, which rather relates to temporary feelings of involvement. We decided to focus on this part of involvement, as it is more related to how people are and not so much to how they feel in a particular situation. This is more in line with research on smoking behavior that demonstrates an increased defensiveness toward provided anti-smoking arguments, only when individuals feel that smoking is important for their identity (Falomir et al., 2002; Freeman et al., 2001).

To test our hypotheses, as a first step, we compared self-persuasion with a direct influence attempt (i.e. providing people with arguments) and a baseline condition in which no influence attempt was performed, by conducting an experimental field-study that allowed us to test the effectiveness of self-persuasion within a highly ecologically valid paradigm. Specifically, we examined to what extent consumers would increase their tipping behavior when they would generate pro-tipping arguments themselves, compared to when pro-tipping arguments would be provided or where not present at all. Subsequently, in a second study, we addressed the current gap in the literature about boundary conditions of the efficacy of self-persuasion. In doing so, we explored the possible moderating role of consumers' involvement with the behavior in the effectiveness of self-persuasion.

\section{Study 1}

Method

Participants and design. In total, 106 guests of a lunchroom in the city center of a Dutch city participated in the experiment. Participants were randomly assigned to one of the conditions of the single-factor (self-persuasion vs provided arguments vs control) between-subjects design.

Procedure and materials. After the guests asked for the bill, the waitress (all female) asked whether they were willing to fill out a questionnaire for a "consumer satisfaction study, in collaboration with the university", which they can complete while waiting for the bill. As part of the cover story, the first part of the questionnaire consisted of several general questions such as "To what extent is good service in a restaurant important to you?" and "How important is the price-quality ratio of the food to you?" This first part was important to ensure that consumers in all conditions took some effort before tipping, to rule out effort or demand effects.

The last part of the questionnaire, however, was different in each condition and was the actual manipulation. In the self-persuasion condition, the guests were asked to write down two reasons why, they thought, a waitress deserves a tip. In the provided argument condition, participants were provided with two arguments why waitresses deserve a tip, embedded in a cover story (see Appendix A). These two arguments resulted from a pilot study in which these arguments were the most frequent responses to the question why waitresses deserve a tip (none of the participants of the pilot study participated in the present study). Guests in the control condition only received the general questions described above.

The waitresses did not know what the purpose of the different conditions was. They were instructed to ensure that the guest who filled in the questionnaire was always the one who
Self-persuasion as marketing technique

1079 
EJM

$51,5 / 6$

1080

subsequently paid. When guests finished the questionnaire, they folded it and handed it to the waitress, together with their payment. Subsequently, the waitress thanked the guests and wrote down the size of the bill, the tip size and whether the guest paid by card or cash. As we aimed to design this field experiment to be as non-intrusive as possible and did not want to decrease its ecological validity, we did not ask for demographics in the questionnaire.

Results

In accordance with the fourth-spread outlier test (Hoaglin et al., 1983), four cases were considered to be outliers and were consequently removed from the sample. All of these guests gave a higher tip than the sum of the 75th percentile and two times the interquartile range within conditions (Ingelfinger, 1994).

As the tip size $D(106)=0.20, p<0.001$, was significantly non-normally distributed, the sample was bootstrapped with a number of 1,000 samples in all subsequent analyses. By bootstrapping the sample, data that are not normally distributed can be analyzed with common parametric tests (Efron and Tibshirani, 1993). To control for the possibility that the tip size was dependent on the total amount of the bill, this was added as a covariate in the subsequent analysis of covariance[2].

The total amount of the bill was significantly related to the size of the tip $F(1,97)=32.68$, $p<0.001, \eta_{\mathrm{p}}{ }^{2}=0.25$. There was also a significant effect of the experimental condition on the size of the tip, after controlling for the effect of the amount of the bill, $F(3,97)=4.00, p=0.01$, $\eta_{\mathrm{p}}{ }^{2}=0.11$ (Figure 1). Supporting H1, post hoc comparison using the Sidak correction indicated that the mean tip in the self-persuasion condition $(\mathrm{M}=€ 1.10$; $\mathrm{SD}=1.06)$ was significantly higher than that in the control condition $(\mathrm{M}=€ 0.41 ; \mathrm{SD}=0.56 ; p=0.005)$ and in the provided arguments condition $(\mathrm{M}=€ 0.37 ; \mathrm{SD}=0.42 ; p=0.023)$. Furthermore, the size of the tip did not differ between the provided arguments and the control condition $(p>0.05)$. In addition, a logistic regression analysis revealed that none of the manipulations affected whether guests gave a tip, $B=-0.32$, Wald $(1,101)=2.75, p>0.05$.

Additionally, to control for the potential confound that the provided arguments differed from those that consumers suggested, we rated participants' responses from two independent blind raters $(\alpha=0.87)$ on how convincing the arguments that consumers gave are and how convincing the provided arguments are on a seven-point Likert scale $(1=$ not

Figure 1.

The effect of the experimental conditions on the size of the tip

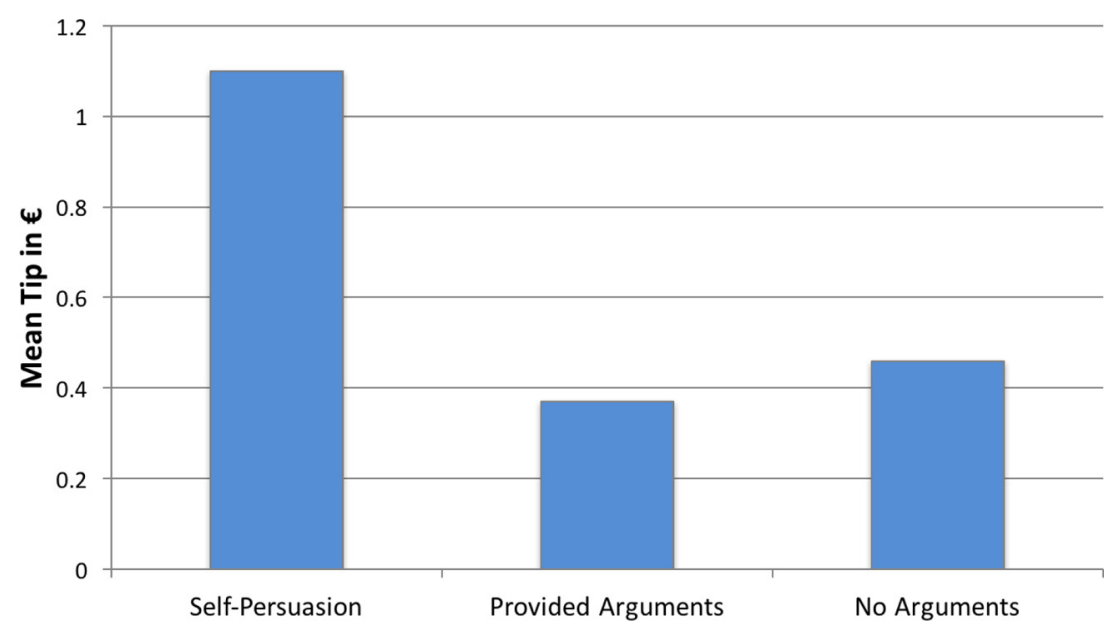


convincing at all; $7=$ totally convincing). As $\alpha$ value was high enough, we calculated a mean score of both scorings. First, written arguments were categorized into six categories (friendly service $n=11$, fast service $n=7$, honest waitress $n=3$, good product knowledge $n=2$, good looking waitress $n=1$, product quality $n=1$ ). We conducted an independent $t$-test with condition (self-persuasion vs provided arguments) as the between-subject factor and the mean score of both raters as the dependent variable. No significant differences were found between conditions, $t(6)=0.382, p=0.715$.

Self-persuasion as marketing technique

1081

\section{Discussion}

Results showed that participants gave higher tips when they were asked to generate pro-tipping arguments themselves (self-persuasion) than when they were exposed to provided arguments or no arguments at all, supporting the notion that self-persuasion is more effective than providing people with arguments to accomplish behavioral change (Müller et al., 2009, 2016). These results suggest that self-persuasion is also an effective means of persuasion in situations in which no behavioral norms are communicated. To test H2, Study 2 investigates the moderating effect of consumers' involvement in tipping behavior on the effectiveness of self-persuasion in a lab experiment.

\section{Study 2}

Method

Participants were undergraduate students $\left(N=131 ; 71.8\right.$ per cent female, $\mathrm{M}_{\text {age }}=23.9$ years $)$ who were recruited online and invited to the University lab to participate in the study. Participants were assigned to one condition of the single-factor (self-persuasion/provided arguments), between-subjects design with the size of the tip as the dependent variable. In the provided arguments' condition, participants received the following information:

Imagine that you are having lunch with a friend in a lunchroom. After lunch, you are getting the check. Your part of the check is $€ 15,65$. Overall, you were satisfied with the service and your lunch was tasty, but you also had the feeling that your waitress could have been a little bit more attentive. You remember that you read a newspaper article about why tips are important for employees in restaurants. This article named as the two most important reasons why one should tip in a restaurant: That waitresses only get paid a very low salary and therefore, the biggest part of their monthly income depends on the tips they get. That a satisfying service deserves a tip.

In the self-persuasion condition, participants received the following instruction:

Imagine that you are having lunch with a friend in a lunchroom. After lunch, you are getting the check. Your part of the check is $€ 15,65$. Overall, you were satisfied with the service and your lunch was tasty, but you also had the feeling that your waitress could have been a little bit more attentive.

Please write down [in the boxes below] two reasons why waitresses deserve a tip.

After the manipulation, consumers' involvement with tipping was measured by asking participants to indicate to what extent they agreed to the statement "Tipping is important for the way I see myself" $(1=$ totally disagree, $7=$ totally agree; $\mathrm{M}=3.53 ; \mathrm{SD}=1.70)$. This item was adopted from Higie and Feick's (1986) enduring involvement scale. Subsequently, participants were asked how much they would give in the aforementioned situation. Tip size was measured using a slider scale, ranging from $€ 0-10$. Finally, some demographics were assessed.

\section{Results}

To test $H 2$, we conducted a moderation analysis with 5,000 bootstrap resamples using Hayes' (2013) SPSS macro PROCESS. Self-persuasion (vs provided arguments), consumers' involvement with tipping and their interaction were the independent variables and the size of 
EJM

$51,5 / 6$

1082
Figure 2.

Tip size as a function of consumers' involvement with tipping and self-persuasion (vs provided arguments) the tip was the dependent variable. As the sample was mainly female, we also controlled for gender to preclude that our results would be affected by the skewed distribution of gender. This analysis revealed a significant positive main effect of consumers' involvement with tipping, $(B=0.16$, 95 per cent $\mathrm{BCBCI}[0.08 ; 0.24])$ and, importantly, an interaction between involvement and self-persuasion, $(B=0.09$, 95 per cent BCBCI [0.01; 0.17]; Figure 2$)$. All other variables did not reach statistical significance.

Supporting H2, a floodlight analysis using the Johnson-Neyman technique demonstrated that if consumers had low-to-moderate involvement with tipping, there was no difference between the experimental conditions. When consumers were highly involved with tipping (with an involvement score of 5.90 or higher), however, those who were in the self-persuasion condition gave a higher tip than those who were exposed to externally generated arguments $(B=0.24,95$ per cent BCBCI $[0.00 ; 0.48])$.

To preclude that there would be an effect of our manipulation on self-involvement, we tested this relationship. Results demonstrate that participants in the self-persuasion condition $(\mathrm{M}=4.06 ; \mathrm{SD}=1.31)$ and those in the provided arguments condition $(\mathrm{M}=3.81$; $\mathrm{SD}=1.34$ ) did not differ in their involvement with the target behavior, $t(129)=-1.085, p=$ 0.28 .

Additionally, to control for the potential confound that the provided arguments differed from those that consumers suggested, we rated participants' responses from two independent blind raters $(\alpha=0.77)$ on how convincing the arguments that consumers gave are and how convincing the provided arguments are on a seven-point Likert-type scale $(1=$

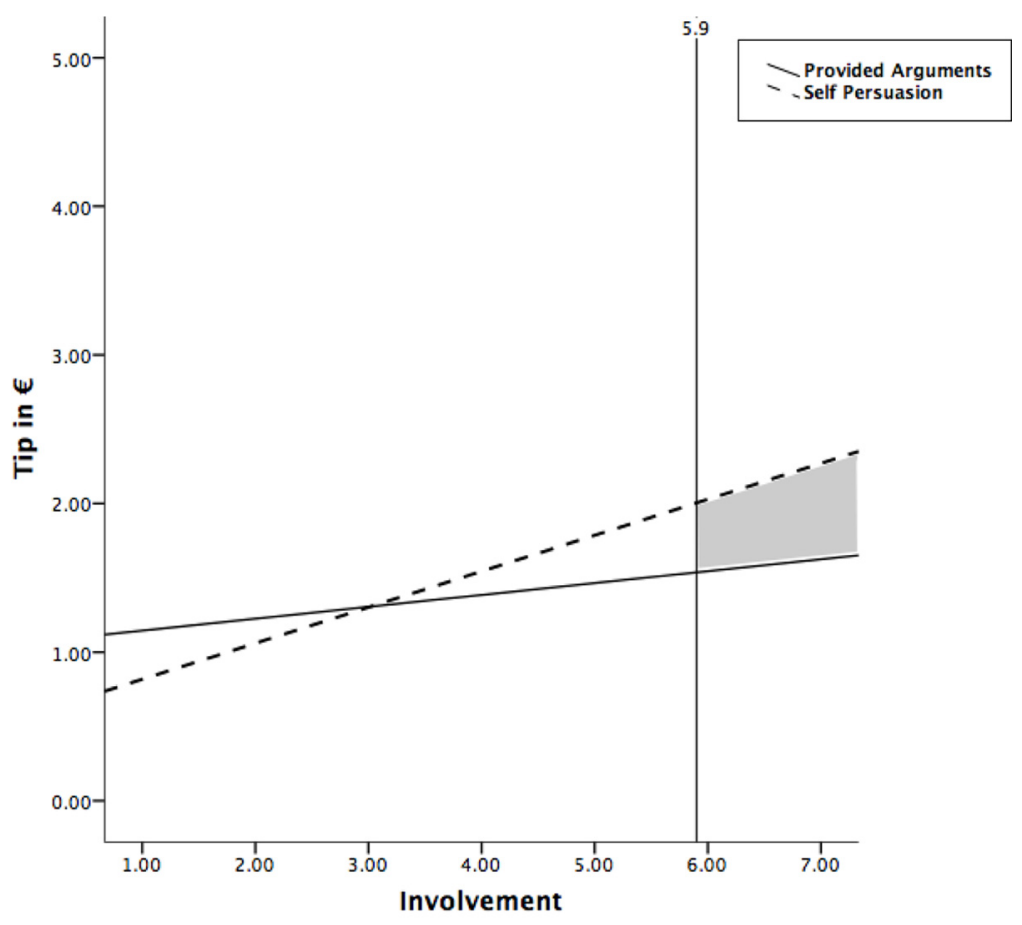

Note: The gray area is the significant confidence region 
not convincing at all; $7=$ totally convincing). As $\alpha$ value was high enough, we calculated a mean score of both scorings. First, written arguments were categorized into six categories (good service $n=52$, hard work $n=23$, friendly waitress $n=20$, low salary $n=20$, it is the social norm $n=6$ and it is nice $n=6$ ). We conducted an independent $t$-test with condition (self-persuasion vs provided arguments) as between-subject factor and the mean score of both raters as dependent variable. No significant differences were found between conditions, $t(6)=0.442, p=0.674$.

Self-persuasion as marketing technique

1083

\section{Discussion}

These results demonstrate that the effects of self-persuasion are conditional on consumers' involvement with the target behavior. When consumers were highly involved with tipping, self-persuasion was considerably more effective than provided arguments. For low- and moderate-involvement consumers, however, the effects of self-persuasion compared to provided arguments did not differ, indicating that self-persuasion is a technique that is particularly valuable in situations in which consumers are highly involved with the target behavior.

\section{General discussion}

The results confirm that self-persuasion is a powerful influence technique, which positively affects consumers' behavior. In Study 1, we showed that participants gave higher tips when they were asked to generate pro-tipping arguments themselves (self-persuasion) than when they were exposed to provided arguments or no arguments at all. These results are in line with existing studies on self-persuasion, which suggest that self-persuasion is more effective than providing people with arguments to accomplish behavioral change (Müller et al., 2009, 2016). In Study 2, it was demonstrated that self-persuasion increases tipping behavior, especially when individuals are highly involved with the behavior (i.e. when tipping behavior is important to the way they see themselves). However, for individuals who were moderately or not involved with tipping behavior, providing arguments as to why tipping is important was as effective as self-persuasion. These results are in line with research on smoking behavior that demonstrates an increased defensiveness toward provided anti-smoking arguments, only when individuals are highly involved with the behavior (i.e. smoking was important for their identity; Falomir et al., 2002; Freeman et al., 2001). Similarly, our results show that the effectiveness of providing arguments decreases for high-involved individuals in the domain of consumer behavior. In doing so, our results provide an explanation for the high efficacy of self-persuasion that has been demonstrated in previous studies; the great majority of these studies dealt with behavior that is highly involving and self-relevant (Glock et al., 2013; Müller et al., 2009).

Going beyond the current literature on self-persuasion, which demonstrated that self-persuasion affects addictive behavior, the present studies show, for the first time, that self-persuasion works better than directly formulated injunctive norms for behavior that is less subject to the communication of injunctive norms than is the case for addictive behaviors such as smoking. Based on these findings, we can rule out the possibility that the promising positive effects of self-persuasion from previous research are related and limited to these kind of behaviors (as, for example, smoking; see Falomir and Invernizzi 1999).

Importantly, we showed that self-persuasion is also effective in a real field setting with a representative consumer sample. As we aimed to design the field experiment to be as non-intrusive as possible, we unfortunately have no demographic data about the participants of the field experiment, making it difficult to assess other differences between the experimental groups. However, as the assignment of the experimental conditions was random, we do not expect significant differences between these groups. 
EJM

$51,5 / 6$

1084

Moreover, with Study 2, we can provide demographics of the participants, which supports the notion that it is unlikely that differences in demographics are responsible for findings of our field study.

From the literature on social influence, we know that a well-known and effective indirect technique that is closely related to self-persuasion is to just show people arguments that are hard to deny and letting them agree to these. It has been demonstrated that this technique relies on the principle of commitment and consistency $(\mathrm{C} \& \mathrm{C}$; for an overview, see Cialdini 2009). This C\&C principle uses the human desire to appear consistent in attitude and behavior. After committing, people are more likely to act in line with the statement provided earlier (Brownstein et al., 2004; Cialdini and Goldstein, 2004; Russo et al., 2006). The persuasive power of this technique can be explained by the theory of cognitive dissonance (Festinger, 1957), which states that saying or doing something that runs counter to peoples' own beliefs evokes an uncomfortable feeling when people are aware of this dissonance. Individuals try to reduce this dissonance by bringing these disparate cognitions into greater harmony. Thus, while people can easily deny requests that are based on provided arguments, it is much harder for them to deny requests in line with statements to which they committed before. However, the principle of $\mathrm{C} \& \mathrm{C}$ requires that people still commit to information that is provided by an external source. While $\mathrm{C} \& \mathrm{C}$ asks people to commit to a certain statement, self-persuasion goes a step further by letting people generate arguments themselves. That is, self-persuasion might be interpreted as a stronger form of $\mathrm{C} \& \mathrm{C}$, as people are persuaded by information that is provided by themselves rather than someone else. Therefore, it would be interesting to compare effects of self-persuasion with those of $\mathrm{C} \& \mathrm{C}$ and investigate whether their efficacy relies on different mechanisms.

In the present studies, it is demonstrated that self-persuasion could positively affect the size of the tip that people give but not whether they give a tip. However, research on habit shows that behavior that has already been performed in the past is more likely to be performed than behavior that has not been performed before (Aarts et al., 1998; Ouellette and Wood, 1998). Consequently, it would be interesting to investigate whether self-persuasion is also able to elicit spontaneous behavior rather than just changing existing behavioral patterns. In other words, could self-persuasion influence people to engage in behaviors they did not intend to engage in, rather than just influence behavior they would have engaged in, anyway? And are there possibly different processes at play, which explain the different effects on habitual and spontaneous behavior? We recommend that further research should address this issue.

In addition to the above, it might be argued that self-persuasion could possibly also have a more stable or durable effect than other techniques of persuasion in the long term, as self-persuasion entails people generating the arguments themselves, and people are therefore likely to be more self-involved with these arguments (Müller et al., 2009). Therefore, an interesting question is whether there would be a difference between self-persuasion and other techniques when the timespan between the persuasion attempt and behavior, which was only a few minutes in Study 2, would be extended. Additionally, research has shown that self-persuasion can have negative side effects; when simply asking for screening questions (e.g. whether about adolescents smoking habits, alcohol consumption or drug use), this can increase the behavior in question (Fitzsimons and Moore, 2008). It would also be interesting to test the effects of communication of behavioral norms on the efficacy of self-persuasion, as these might constitute an interesting situational boundary condition. Thus, it is essential to further investigate other boundary conditions besides involvement that make self-persuasion an effective tool. 
Some limitations of the present studies need to be addressed. First, involvement was measured with a single-item measure instead of a multi-item scale. We decided to use a single-item scale for two reasons: First, because we measured involvement between the manipulation and the dependent variable and wanted to avoid that this measurement would consume too much time and might potentially weaken the effects of our manipulation. Second, many of the items of Higie and Feick (1986) were either not relevant for the investigated target behavior (e.g. fun, interesting, exciting, appealing and fascinating) or focusing on the public and observable part of enduring involvement (e.g. tells me about a as marketing technique person, others use to judge me, tells others about me and portrays an image of me to others). As tipping (at least in The Netherlands where this study was conducted) is a rather private type of behavior, the public component of it would harm the internal validity of our measurement. In the literature, there is some discord regarding the predictive validity of single- (vs multi-) item scales. While research demonstrated that a single item can reach the predictive validity of a multi-item scale and should be preferred in situations in which a construct can be considered to be concrete (e.g. Bergkvist and Rossiter, 2007, 2009), others argue that multi-item scales should always be the preferred choice (Churchill, 1979). Therefore, future research should consider using a multi-item scale, especially if a small sample size is used $(N<50)$, weak effect sizes are expected and items are highly heterogeneous (Cronbach's $\alpha>0.90$ ) and not semantically redundant (Diamantopoulos et al., 2012).

Second, involvement was measured in-between the experimental condition and the dependent variable in Study 2. While we could statistically rule out that the experimental conditions affected consumers' involvement, one might still argue that the involvement measurement could have possibly worked as prime rather than a trait and might therefore confound our results. Such primes would be able to explain the main effect of consumers' involvement on their tipping behavior but would not be able to explain the interaction between the experimental conditions and consumers' involvement that is at the heart of Study 2. In spite of this, future research should still consider to measure involvement after the measurement of the dependent variable to fully avoid possible confounds like this.

To conclude, our two studies demonstrated that self-persuasion is a very effective technique to increase consumers' generosity and is considerably more effective than direct influence attempts. The scope of self-persuasion is thus not limited to the inhibition of addictive behavior but does also extend to the facilitation of desired consumer behavior, which considerably broadens the scope of this technique. Caution should be taken, however, when generalizing these results to the broader domain of consumer behavior, as the topic of these studies was tipping behavior in particular. As tipping behavior may be liable to, for instance, social desirability or costumer experiences (Rind and Bordia, 1996) and also willingness to spend (Kim et al., 2009), more research is necessary to determine the types of consumer behavior for which self-persuasion proves effective. For instance, self-persuasion might be a particularly worthwhile tool for persuading highly involved consumers. As our study demonstrates an increased efficacy of self-persuasion when consumers are highly involved, self-persuasion may be most effective when applied to high-involvement products, such as holidays, cars and insurances (Percy and Donovan, 1991). In addition, as it has been demonstrated that self-persuasion is also very effective in a mass-media context by framing arguments as questions and presenting these questions to an audience (Glock et al., 2013; Müller et al., 2016), self-persuasion may even be considered to be a means for mass media campaigning or advertising. For instance, with phrases like "Fun, anyone?" (Sony PlayStation), "What would you do for a Klondike bar?" (Klondike) and "Where do you want to go today?" (Microsoft), some major brands already framed their taglines as a question. To 
date, there is no research that addresses the possible effects of such framing on self-persuasion processes among consumers.

Another possibility for brands might be to start marketing campaigns that give consumers the possibility to win prizes by answering such questions, for instance on social media platforms. Marketers may then generate content on their social media pages, where they explicitly ask consumers to generate and post arguments in favor of their brand in return for a small gift or prize (e.g. "What are your reasons to use our brand?"). Besides being able to spread this user-generated content among their network, the self-generated aspect of pro-brand arguments may strengthen brand attitudes and consumer loyalty.

\section{Notes}

1. Contrary to, for instance, the USA, in The Netherlands, where this research has been conducted, there are no specific injunctive or descriptive norms about tipping. Moreover, it is usual in The Netherlands to only give waiters and waitresses a tip when the guest is satisfied with their service.

2. We also conducted an ANOVA, with tip size expressed as a percentage of the total size of the bill as the dependent variable, which led to similar results: $F(3,98)=3.57, p=0.017, \eta_{\mathrm{p}}{ }^{2}=0.10$.

\section{References}

Aarts, H., Verplanken, B. and Knippenberg, A. (1998), "Predicting behavior from actions in the past: repeated decision making or a matter of habit?", Journal of Applied Social Psychology, Vol. 28 No. 15, pp. 1355-1374.

Aronson, E. (2007), "The evolution of cognitive dissonance theory: a personal appraisal", in Pratkanis, A.R. (Ed.), The Science of Social Influence: Advances and Future Progress, Psychology Press, New York, NY, pp. 115-135.

Bergkvist, L. and Rossiter, J.R. (2007), "The predictive validity of multiple-item versus single-item measures of the same constructs“, Journal of Marketing Research, Vol. 44 No. 2, pp. 175-184.

Bergkvist, L. and Rossiter, J.R. (2009), "Tailor-made single-item measures of doubly concrete constructs“, International Journal of Advertising, Vol. 28 No. 4, pp. 607-621.

Brehm, J.W. (1966), A Theory of Psychological Reactance, Academic Press, New York, NY.

Brownstein, A.L., Read, S.J. and Simon, D. (2004), "Bias at the racetrack: effects of individual expertise and task importance on predecision reevaluation of alternatives", Personality \& Social Psychology Bulletin, Vol. 30 No. 7, pp. 891-904.

Burger, J.M. (1999), "The foot-in-the-door compliance procedure: a multiple-process analysis and review", Personality and Social Psychology Review, Vol. 3 No. 4, pp. 303-325.

Burger, J.M. and Petty, R.E. (1981), “The low-ball compliance technique: task or person commitment?”, Journal of Personality and Social Psychology, Vol. 40 No. 3, pp. 492-500.

Churchill, G.A., Jr. (1979), "A paradigm for developing better measures of marketing constructs“, Journal of Marketing Research, Vol. 16 No. 1, pp. 64-73.

Cialdini, R.B. (2009), Influence: Science and Practice, Book, 5th ed., Pearson Education, doi: 10.2307/ 3151490 .

Cialdini, R.B. and Goldstein, N.J. (2004), "Social influence: compliance and conformity", Annual Review of Psychology, Vol. 55, pp. 591-621.

Cialdini, R.B., Cacioppo, J.T., Bassett, R. and Miller, J.A. (1978), "Low-ball procedure for producing compliance: commitment then cost", Journal of Personality and Social Psychology, Vol. 36, pp. $463-476$.

Cialdini, R.B., Vincent, J.E., Lewis, S.K., Catalan, J., Wheeler, D. and Darby, B.L. (1975), "Reciprocal concessions procedure for inducing compliance: the door-in-the-face technique", Journal of Personality and Social Psychology, Vol. 31, pp. 206-215. 
Damen, T.G.E., Müller, B.C.N., van Baaren, R.B. and Dijksterhuis, A. (2015), "Re-examining the agentic shift: the sense of agency influences the effectiveness of (Self)persuasion", PLoS ONE, Vol. 10 No. 6, p. e0128635.

Davis, B.P. and Knowles, E.S. (1999), "A disrupt-then-reframe technique of social influence”, Journal of Personality and Social Psychology, Vol. 76 No. 2, pp. 192-199.

Diamantopoulos, A., Sarstedt, M., Fuchs, C., Wilczynski, P., and Kaiser, S. (2012), "Guidelines for choosing between multi-item and single-item scales for construct measurement: a predictive validity perspective", Journal of the Academy of Marketing Science, Vol. 40, pp. 434-449.

Self-persuasion

as marketing technique

Efron, B. and Tibshirani, R.J. (1993), An Introduction to the Bootstrap, Chapman \& Hall, New York, NY, doi: 10.1111/1467-9639.00050.

Falomir, J.M. and Invernizzi, F. (1999), "The role of social influence and smoker identity in resistance to smoking cessation”, Swiss Journal of Psychology, Vol. 58 No. 20, pp. 73-84.

Falomir, J.M., Invernizzi, F., Mugny, G., Muños-Rojas, D. and Quiamzade, A. (2002), "Social influence on intention to quit smoking: the effect of the rhetoric of an identity relevant message", Revue Internationale de Psychologie Sociale, Vol. 15 No. 1, pp. 81-96.

Fennis, B.M., Das, E.H. and Pruyn, A.T.H. (2004), "If you can't dazzle them with brilliance, baffle them with nonsense': extending the impact of the disrupt-then-reframe technique of social influence", Journal of Consumer Psychology, Vol. 14 No. 3, pp. 280-290.

Fennis, B.M., Janssen, L. and Vohs, K.D. (2009), "Acts of benevolence: a limited-resource account of compliance with charitable requests", Journal of Consumer Research, Vol. 35 No. 6, pp. 906-924.

Festinger, L. (1957), A Theory of Cognitive Dissonance, University Press, Stanford, CA.

Fitzsimons, G.J. and Moore, S.G. (2008), "Should we ask our children about sex, drugs and rock \& roll?: potentially harmful effects of asking questions about risky behaviors", Journal of Consumer Psychology, Vol. 18 No. 2, pp. 82-95.

Fitzsimons, G.J. and Williams, P. (2000), "Asking questions can change choice behavior: does it do so automatically or effortfully?", Journal of Experimental Psychology: Applied, Vol. 6 No. 3, pp. 195-206.

Fransen, M.L., Verlegh, P.W.J., Kirmani, A. and Smit, E.G. (2015), "A typology of consumer strategies for resisting advertising, and a review of mechanisms for countering them", International Journal of Advertising, Vol. 34 No. 1, pp. 6-16.

Freedman, J.L. and Fraser, S.C. (1966), "Compliance without pressure: the foot-in-the-door technique", Journal of Personality and Social Psychology, Vol. 4 No. 2, pp. 195-202.

Freeman, M.A., Hennessy, E.V. and Marzullo, D.M. (2001), "Defensive evaluation of antismoking messages among college-age smokers: the role of possible selves", Health Psychology, Vol. 20 No. 6, pp. 424-433.

Gamliel, E. and Herstein, R. (2012), "Effects of message framing and involvement on price deal effectiveness null”, European Journal of Marketing, Vol. 46 No. 9, pp. 1215-1232.

Glock, S. and Kneer, J. (2009), "Are deterrent pictures effective? The impact of warning labels on cognitive dissonance in smokers", Applied Psychology: Health and Well-Being, Vol. 1 No. 3, pp. 356-373.

Glock, S., Müller, B.C.N. and Ritter, S. (2013), "Warning labels formulated as questions positively influence smoking-related risk perception", Journal of Health Psychology, Vol. 18 No. 2, pp. 252-262.

Greenwald, A.G. and Albert, R.D. (1968), "Acceptance and recall of improvised arguments", Journal of Personality and Social Psychology, Vol. 8 No. 1, pp. 31-34.

Hamilton, W.L., Biener, L. and Brennan, R.T. (2008), "Do local tobacco regulations influence perceived smoking norms? Evidence from adult and youth surveys in Massachusetts", Health Education Research, Vol. 23 No. 4, pp. 709-722. 
EJM

$51,5 / 6$

1088

Hayes, A.F. (2013), Introduction to Mediation, Moderation, and Conditional Process Analysis: A Regression-Based Approach, Guilford Press, New York, NY, doi: 978-1-60918-230-4.

Higie, R.A. and Feick, L.F. (1989), "Enduring involvement: conceptual and measurement issues", in Thomas, K.S. and Provo, U.T. (Eds), Advances in Consumer Research, Association for Consumer Research, Urbana, IL, Vol. 16, pp. 690-696.

Hoaglin, D.C., Mosteller, F. and Tukey, J.W. (1983), Understanding Robust and Exploratory Data Analysis, John Wiley \& Sons, New York, NY, doi: 10.1214/ss/1076102418.

Hoch, S.J. and Deighton, J. (1989), "Managing what consumers learn from experience", Journal of Marketing, Vol. 53 No. April, pp. 1-20.

Ingelfinger, J.A. (1994), Biostatistics in Clinical Medicine, McGraw-Hill, New York, NY.

Johnson, B.T. and Eagly, A.H. (1989), "Effects of involvement on persuasion: a meta-analysis", Psychological Bulletin, Vol. 106 No. 2, pp. 290-314.

Kardes, F.R., Cronley, M.L., Pontes, M.C. and Houghton, D.C. (2001), "Down the garden path: the role of conditional inference processes in self-persuasion”, Journal of Consumer Psychology, Vol. 11 No. 3, pp. 159-168.

Kim, J.Y., Natter, M., and Spann, M. (2009), "Pay what you want: a new participative pricing mechanism", Journal of Marketing, Vol. 73 No. 1, pp. 44-58.

Knowles, E.S. and Linn, J.A. (2004), “The importance of resistance to persuasion”, in Knowles, E.S. and Linn, J.A. (Eds), Resistance and Persuasion, Erlbaum, Mahwah, NJ, pp. 3-11.

Krischler, M. and Glock, S. (2015), "Alcohol warning labels formulated as questions change alcohol-related outcome expectancies: a pilot study”, Addiction Research \& Theory, Vol. 23 No. 4, pp. 343-349.

Krishen, A.S., Raschke, R., Kachroo, P., LaTour, M. and Verma, P. (2014), "Promote me or protect us? The framing of policy for collective good”, European Journal of Marketing, Vol. 48 No. 3/4, pp. 742-760.

Levin, I.P., Chapman, D.P. and Johnson, R.D. (1988), "Confidence in judgments based on incomplete information: an investigation using both hypothetical and real gambles", Journal of Behavioral Decision Making, Vol. 1 No. 1, pp. 29-41.

Liberman, A. and Chaiken, S. (1992), "Defensive processing of personally relevant health messages", Personality and Social Psychology Bulletin, Vol. 18 No. 6, pp. 669-679.

Loman, J.G.B., Oude Groote Beverbog, A., Müller, B.C.N. and Buijzen, M.A. (2015), "Self-persuasion in health communication: reducing alcohol consumption by framing anti-alcohol messages as questions.”, Annual Conference of the International Communication Association (ICA), San Juan.

Lunardo, R. and Roux, D. (2015), "In-store arousal and consumers' inferences of manipulative intent in the store environment”, European Journal of Marketing, Vol. 49 No. 5/6, pp. 646-667.

McKechnie, S., Devlin, J., Ennew, C. and Smith, A. (2012), "Effects of discount framing in comparative price advertising null”, European Journal of Marketing, Vol. 46 No. 11/12, pp. 1501-1522.

Müller, B.C.N., van Baaren, R.B., Ritter, S.M., Woud, M.L., Bergmann, H., Harakeh, Z., Engels, R.C. and Dijksterhuis, A. (2009), "Tell me why...The influence of self-involvement on short term smoking behaviour", Addictive Behaviors, Vol. 34 No. 5, pp. 427-431.

Müller, B.C.N., van Someren, D.H., Gloudemans, R.T.M., van Leeuwen, M.L., and Greifeneder, R. (in press), "Helping made easy: ease of argument generation enhances intentions to help", Social Psychology.

Müller, B.C.N., Ritter, S.M., Glock, S., Dijksterhuis, A., Engels, R.C. and van Baaren, R.B. (2016), "Smoking-related warning messages formulated as questions positively influence short-term smoking behaviour", Journal of Health Psychology, Vol. 21 No. 1, pp. 60-68. 
Mussweiler, T. and Neumann, R. (2000), "Sources of mental contamination: comparing the effects of self-generated versus externally provided primes", Journal of Experimental Social Psychology, Vol. 36 No. 2, pp. 194-206.

Ouellette, J.A. and Wood, W. (1998), "Habit and intention in everyday life: the multiple processes by which past behavior predicts future behavior", Psychological Bulletin, Vol. 124 No. 1, pp. 54-74.

Pascual, A., Guéguen, N., Pujos, S. and Felonneau, M.-L. (2013), "Foot-in-the-door and problematic requests: a field experiment", Social Influence, Vol. 8 No. 1, pp. 46-53.

Percy, L., and Donovan, R.J. (1991), “A better advertising planning grid”, Journal of Advertising Research, Vol. 31, pp. 11-21.

Petty, R.E. and Cacioppo, J.T. (1979), "Issue involvement can increase or decrease persuasion by enhancing message-relevant cognitive responses", Journal of Personality and Social Psychology, Vol. 37 No. 10, pp. 1915-1926.

Petty, R.E., Cacioppo, J.T. and Goldman, R. (1981), "Personal involvement as a determinant of argument-based persuasion", Journal of Personality and Social Psychology, Vol. 41 No. 5, pp. $847-855$.

Petty, R.E., Cacioppo, J.T. and Schumann, D. (1983), "Central and peripheral routes to advertising effectiveness: the moderating role of involvement", Journal of Consumer Research, Vol. 10 No. 2, pp. 135-146.

Richins, M.L. and Bloch, P.H. (1986), "After the new wears off: the temporal context of product involvement”, Journal of Consumer Research, Vol. 13 No. 2, pp. 280-285.

Richins, M.L., Bloch, P.H. and McQuarrie, E.F. (1992), "How enduring and situational involvement combine to create involvement responses", Journal of Consumer Psychology, Vol. 1 No. 2, pp. 143-153.

Rind, B., and Bordia, P. (1996), "Effect on restaurant tipping of male and female servers drawing a happy, smiling face on the backs of customers' checks", Journal of Applied Social Psychology, Vol. 26 No. 3, pp. 218-225.

Russo, J.E., Carlson, K.A. and Meloy, M.G. (2006), “Choosing an inferior alternative”, Psychological Science, Vol. 17 No. 10, pp. 899-904.

Slamecka, N.J. and Graf, P. (1978), “The generation effect: delineation of a phenomenon.”, Journal of Experimental Psychology: Human Learning and Memory, Vol. 4 No. 6, pp. 592-604.

Williams, P., Block, L.G. and Fitzsimons, G.J. (2006), "Simply asking questions about health behaviors increases both healthy and unhealthy behaviors", Social Influence, Vol. 1 No. 2, pp. 117-127.

\section{Corresponding author}

Stefan F. Bernritter can be contacted at: S.F.Bernritter@uva.nl 
EJM

$51,5 / 6$

1090
Appendix

[Logo lunchroom]

[Logo university]

Dear guest,

In collaboration with [University] we are investigating the factors that play a role in customer satisfaction with lunchrooms. We would appreciate it if you are willing to fill out this short questionnaire, which will take only two minutes of your time. It is important that this questionnaire is filled out by the person who pays the bill.

Thank you in advance!

Please circle the answer that applies to you.

In my opinion, the quality of the products in a lunchroom is more important than the price Totally Disagree

-2-

$-3$.

$-4$ Totally Agree

For me, a good service is more important than low prices

$\begin{array}{ccccc}-1- & -2- & -3- & -4- & -5- \\ \text { Totally Disagree } & & & & \text { Totally Agree }\end{array}$

When I order, I like to receive advice about the dishes

$\begin{array}{ccccc}-1- & -2- & -3- & -4- & -5- \\ \text { Totally Disagree } & & & & \text { Totally Agree }\end{array}$

Ilike to try new dishes

-1 -

Totally Disagree

$-2-$

$-3-$

$-4$

-5-

Totally Agree

When I am eating in a lunchroom, the atmosphere is really important for me

-1 -

$-2$

$-3-$

$-4-$

-5 -

Totally Agree

In another study, people mentioned the following reasons why waitresses should deserve a tip:

- A good, customer directed service is worth a tip.

- Waitresses receive little salary in relation to the work load, for which tipping is a compensation.

Thank you for filling out this questionnaire!

Example of the manipulation in the provided arguments condition (translated into English). 